\title{
Trypsin/Chymotrypsin Protein Cleavage Reagent
}

National Cancer Institute

\section{Source}

National Cancer Institute. Trypsin/Chymotrypsin Protein Cleavage Reagent. NCI

Thesaurus. Code C161892.

A protein cleavage reagent comprised of a mixture of trypsin and chymotrypsin that cleaves proteins into peptides at the C-terminal side of a phenylalanine, tyrosine, tryptophan, leucine, lysine or arg inine residue unless that residue is followed by a proline. 